\title{
Effect of dietary pulse intake on established therapeutic lipid targets for cardiovascular risk reduction: a systematic review and meta-analysis of randomized controlled trials
}

\author{
Vanessa Ha MSc, John L. Sievenpiper MD PhD, Russell J. de Souza ScD, Viranda H. Jayalath HBSc, \\ Arash Mirrahimi MSc, Arnav Agarwal, Laura Chiavaroli MSc, Sonia Blanco Mejia MD, Frank M. Sacks MD, \\ Marco Di Buono PhD, Adam M. Bernstein MD ScD, Lawrence A. Leiter MD, Penny M. Kris-Etherton PhD, \\ Vladimir Vuksan PhD, Richard P. Bazinet PhD, Robert G. Josse MBBS, Joseph Beyene PhD, \\ Cyril W.C. Kendall PhD, David J.A. Jenkins MD DSC
}

Competing interests: See end of article.

This article has been peer reviewed.

Correspondence to:

John Sievenpiper

john.sievenpiper@

utoronto.ca

CMAJ 2014. DOI:10.1503 /cmaj.131727

\begin{abstract}
Background: Evidence from controlled trials encourages the intake of dietary pulses (beans, chickpeas, lentils and peas) as a method of improving dyslipidemia, but heart health guidelines have stopped short of ascribing specific benefits to this type of intervention or have graded the beneficial evidence as low. We conducted a systematic review and metaanalysis of randomized controlled trials (RCTs) to assess the effect of dietary pulse intake on established therapeutic lipid targets for cardiovascular risk reduction.
\end{abstract}

Methods: We searched electronic databases and bibliographies of selected trials for relevant articles published through Feb. 5, 2014. We included RCTs of at least 3 weeks' duration that compared a diet emphasizing dietary pulse intake with an isocaloric diet that did not include dietary pulses. The lipid targets investigated were low-density lipopro- tein (LDL) cholesterol, apolipoprotein B and non-high-density lipoprotein (non-HDL) cholesterol. We pooled data using a randomeffects model.

Results: We identified 26 RCTs $(n=1037)$ that satisfied the inclusion criteria. Diets emphasizing dietary pulse intake at a median dose of $130 \mathrm{~g} / \mathrm{d}$ (about 1 serving daily) significantly lowered LDL cholesterol levels compared with the control diets (mean difference $-0.17 \mathrm{mmol} / \mathrm{L}, 95 \%$ confidence interval -0.25 to $-0.09 \mathrm{mmol} / \mathrm{L}$ ). Treatment effects on apolipoprotein B and non-HDL cholesterol were not observed.

Interpretation: Our findings suggest that dietary pulse intake significantly reduces LDL cholesterol levels. Trials of longer duration and higher quality are needed to verify these results. Trial registration: ClinicalTrials.gov, no. NCT01594567.
A bnormal blood concentrations of lipids are one of the most important modifiable risk factors for cardiovascular disease. Although statins are effective in reducing low-density lipoprotein (LDL) cholesterol levels, major health organizations have maintained that the initial and essential approach to the prevention and management of cardiovascular disease is to modify dietary and lifestyle patterns. ${ }^{1-4}$

Dietary non-oil-seed pulses (beans, chickpeas, lentils and peas) are foods that have received particular attention for their ability to reduce the risk of cardiovascular disease. Consumption of dietary pulses was associated with a reduction in cardiovascular disease in a large observational study ${ }^{5}$ and with improvements in LDL cholesterol levels in small trials. ${ }^{6-8}$ Although most guidelines on the prevention of major chronic diseases encourage the consumption of dietary pulses as part of a healthy strategy,,$^{2,39-13}$ none has included recommendations based on the direct benefits of lowering lipid concentrations or reducing the risk of cardiovascular disease. In all cases, the evidence on which recommendations have been based was assigned a low grade,,$^{2,39-13}$ and dyslipidemia guidelines do not address dietary pulse intake directly.,4

To improve the evidence on which dietary guidelines are based, we conducted a systematic review and meta-analysis of randomized controlled trials (RCTs) of the effect of dietary pulse intake on established therapeutic lipid targets for cardiovascular risk reduction. The lipid targets were LDL cholesterol, apolipoprotein B and nonhigh-density lipoprotein (non-HDL) cholesterol. 


\section{Methods}

We followed the protocol outlined in the Cochrane Handbook for Systematic Reviews of Interventions. ${ }^{14}$ We report our findings in accordance with the PRISMA (Preferred Reporting Items for Systematic Reviews and Meta-Analyses) statement. ${ }^{15}$ The protocol for our study is available at ClinicalTrials.gov (registration no. NCT01594567).

\section{Data sources}

One of us (V.H.) searched MEDLINE, Embase, the Cochrane Central Register of Controlled Trials and CINAHL databases and manually searched bibliographies of published studies through Feb. 5, 2014, to identify relevant studies. Uncertainty was resolved through discussion and consensus with senior authors (R.J.d.S., J.L.S. and D.J.A.J.). Details of the search strategy are shown in Appendix 1 (available at www.cmaj.ca /lookup/suppl/doi:10.1503/cmaj.131727/-/DC1).

\section{Study selection}

We included RCTs involving any population (healthy or unhealthy) that examined the effects of dietary pulses compared with an isocaloric diet without dietary pulses on LDL cholesterol, apolipoprotein B and non-HDL cholesterol levels. The follow-up period had to have been at least 3 weeks, a duration that satisfies the minimum follow-up requirement of the US Food and Drug Administration (FDA) used in the scientific evaluation of lipid-lowering health claims. ${ }^{16}$ Studies that examined only whole dietary nonoil-seed pulses (beans, chickpeas, lentils and peas) were included. We excluded trials of peanuts and soybeans because of their high oil content, and studies of pulse extracts. We included trials in which dietary pulse intake was not the sole intervention but was the dominant intervention used to achieve the study goals. The selected outcomes included ones that have been identified as therapeutic lipid targets in major American and Canadian cardiovascular and diabetes guidelines..$^{1-4}$

One of the trials that we included was quasi-randomized. ${ }^{17}$ We attempted to reduce bias and reanalyzed the findings from the study by randomly assigning participants to either the treatment or control group in a parallel study design stratified by baseline total cholesterol level and age.

\section{Data extraction and quality assessment}

Studies that met the inclusion criteria had their study characteristics and results extracted by 3 independent reviewers (V.H., R.J.d.S. and V.H.J). An overall 10-year Framingham risk score for coronary artery disease was calculated separately for men and women for each study. ${ }^{1}$ Participants were assumed to be at a higher risk for a particular domain when information for that domain was missing.

We assessed the methodologic quality of each report using the Heyland Methodological Quality Score. ${ }^{18}$ Studies given a score of 8 or higher out of 13 possible points were considered high quality. We also assessed the reports for risk of bias using the Cochrane risk-of-bias tool. ${ }^{19}$ Studies were considered to have a high risk of bias across dimensions if the methodologic flaw was likely to have affected the true outcome, a low risk if the study's methodologic flaw was deemed inconsequential to the true outcome and an unclear risk if insufficient information was provided to assess risk of bias.

All disagreements were resolved by consensus.

\section{Data synthesis and analysis}

We used Review Manager 5.0.25 to analyze the data. We conducted pooled analyses using the generic inverse variance method with randomeffects weighting. Data were expressed as mean differences with 95\% confidence intervals (CIs). To mitigate the unit-of-analysis error from including a trial with multiple intervention arms, ${ }^{20}$ we combined the intervention arms in the trial to create a single pairwise comparison. To impute standard deviations for between-treatment differences in crossover trials, we derived correlation coefficients between baseline and end-of-treatment values within each trial using a published formula. ${ }^{21}$ A correlation of 0.72 was calculated for the analysis of LDL cholesterol; a correlation coefficient of 0.5 was assumed for non-HDL cholesterol owing to a lack of data, with sensitivity analyses done at 0.25 and 0.75 . When trials did not report change-from-baseline differences within or between treatments, or end-differences between treatments, we imputed these values from the available data using standard formulas. ${ }^{14}$ When required, we tried to obtain additional information from the authors of the studies. A 2sided $p$ value of less than 0.05 was set as the level of significance.

When the non-HDL cholesterol level was not reported in a trial, we calculated it from aggregate data by subtracting HDL cholesterol from total cholesterol values.

We used the Cochran $Q$ statistic to assess, and the $I^{2}$ statistic to quantify inter-study heterogeneity (threshold $p<0.10$ ). An $I^{2}$ value of $50 \%$ or higher was considered to be evidence of substantial heterogeneity and a value of $75 \%$ or higher, considerable heterogeneity. We explored sources of heterogeneity using a priori subgroup analyses according to baseline cholesterol values, dose of 
dietary pulse, type of dietary pulse, duration of follow-up, difference in fibre content and saturated fat between the intervention and control diets, study design (crossover or parallel) and methodologic quality score. We also conducted post-hoc subgroup analyses by sex and baseline triglyceride levels to explore sources of interstudy heterogeneity further. To determine whether any single trial exerted an undue influence on the overall results, we conducted sensitivity analyses in which each study was removed and the effect size recalculated.

We assessed publication bias by visually inspecting funnel plots and formally testing their asymmetry using the Begg rank correlation test and the Egger linear regression test. We also used the trim-and-fill method to test for undue

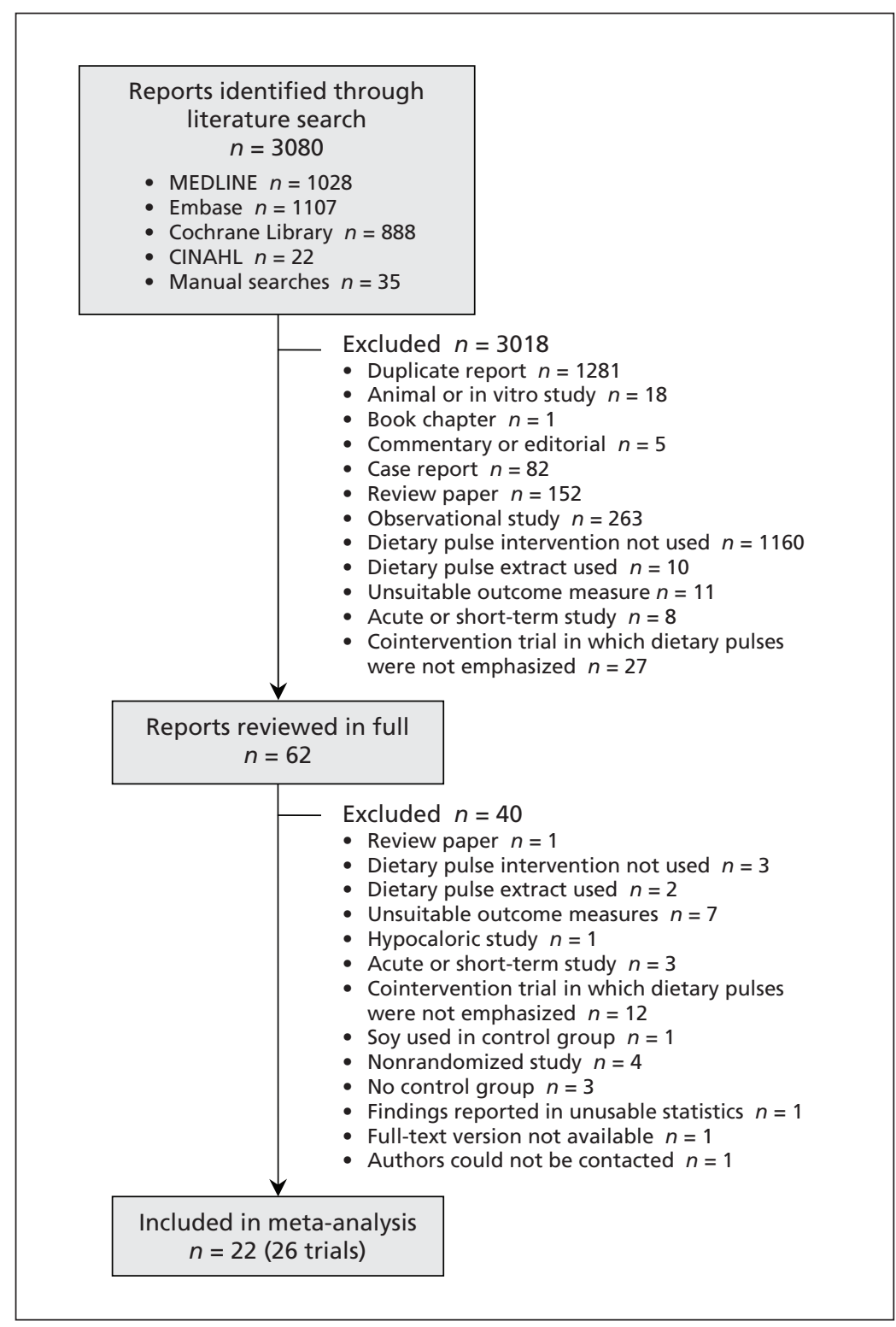

Figure 1: Selection of randomized controlled trials for the meta-analysis. influence of small-study effects on the effect size of our primary analysis.

\section{Results}

\section{Search results and study characteristics}

Our search identified 3080 reports, of which 22 (26 RCTs) were selected for our meta-analysis (Figure 1). ${ }^{6-8,17,20,22-33,34,35,36-38}$

The characteristics of the 26 trials $(n=1037)$ are summarized in Table 1 (the full table of characteristics is available in Appendix 2, at www .cmaj.ca/lookup/suppl/doi:10.1503/cmaj.131727 /-/DC1). Eight trials selected patients with hyperlipidemia, 3 had patients with normal lipid profiles, and 15 trials included a combination. The median age of participants was 51.1 years, and the number of men and women was about equal overall. At baseline, the median LDL cholesterol was $3.50 \mathrm{mmol} / \mathrm{L}$ and non-HDL cholesterol $4.34 \mathrm{mmol} / \mathrm{L}$. Studies had a median of 3 Framingham risk factors associated with risk of coronary artery disease, which implicated a moderate risk level (i.e., 10-year risk $\leq 20 \%$ ). ${ }^{1}$ Three trials were rated as risk equivalent for coronary artery disease $^{1}$ because they involved participants with type 2 diabetes. ${ }^{30,34,35}$

Dietary pulse intake was not the sole intervention but was the dominant intervention used to achieve the study goals in 3 trials. ${ }^{32,34,35}$ Beans were the most common type of dietary pulse used in the intervention diets (14 trials); peas were used in 2 trials, chickpeas in 2 trials, lentils in 1 trial and mixed pulses in 8 trials. Dietary pulses were administered as flour in 3 trials, as whole foods in 18 trials and in a mixed format (flour and whole foods) in 3 trials; the median dose was 130 (range 50-377) g/d. The background diet consisted of 39\%-65\% energy from carbohydrates, $10 \%-35 \%$ from protein and $20 \%-41 \%$ from fat. The median fibre intake was 20 (range 13-47) g/d in the control diets and 26 (range 17-53 g/d) in the intervention diets; the median saturated fat intake was $11 \%$ energy (range 5\%-15\%) in the control diets and $11 \%$ energy (range 5\%-15\%) in the intervention diets.

The method of increasing dietary pulse intake while maintaining caloric balance between the study arms differed across protocols: 15 trials replaced non-dietary pulse carbohydrates (e.g., bread products, canned spaghetti, oat bran), 5 trials replaced animal protein, 3 trials emphasized dietary pulse intake to achieve a low-glycemic diet, and 3 did not specify the method. Three trials were weight-loss interventions designed to reduce total caloric intake by $30 \%-35 \%$. The diets were metabolically controlled (all foods 
Table 1: Characteristics of randomized controlled trials of the effect of dietary pulse intake on established therapeutic lipid targets for cardiovascular risk reduction that were included in the meta-analysis*

\begin{tabular}{|c|c|c|c|c|c|c|c|}
\hline Design; study & Participants; country & $\begin{array}{l}\text { Age, yr, } \\
\text { mean } \pm \text { SD } \\
\text { (range) }\end{array}$ & $\begin{array}{l}\text { Lipid-lowering } \\
\text { drugs used }\end{array}$ & $\begin{array}{l}\text { Foods provided } t \\
\text { (pulse dose, } \\
\text { g/d } \ddagger)\end{array}$ & $\begin{array}{l}\text { Pulse type§ } \\
\text { (and formף) }\end{array}$ & Comparator & $\begin{array}{l}\text { Duration of } \\
\text { follow-up }\end{array}$ \\
\hline \multicolumn{8}{|l|}{ Parallel } \\
\hline Abete et al. ${ }^{6}$ & 18 obese men; Spain & $\sim 37.1 \pm 8.0$ & No & None ( 90) & Mixed (whole) & No pulses & $8 w k$ \\
\hline Anderson et al. ${ }^{22}$ & 20 men with $\mathrm{HC}$; US & $\sim 54 \pm 8.4$ & No & All (101) & Beans (whole) & Oat bran & $3 w k$ \\
\hline Anderson et al. ${ }^{17}(\mathrm{I})$ & 6 men with HC; US & $64 \pm 2.4$ & No & Partial ( 113) & Beans (whole) & No pulses & 3 wk \\
\hline Anderson et al. ${ }^{17}$ (II) & 9 men with HC; US & $57 \pm 9$ & No & Partial ( 113) & Beans (whole) & No pulses & 3 wk \\
\hline Anderson et al. ${ }^{17}$ (III) & 9 men with $\mathrm{HC}$; US & $54 \pm 9$ & No & Partial ( 152) & Beans (whole) & No pulses & $3 \mathrm{wk}$ \\
\hline Belski et al. ${ }^{23}$ & $\begin{array}{l}93(52 \mathrm{M}, 41 \mathrm{~F}) \\
\text { overweight or obese } \\
\text { patients; Australia }\end{array}$ & $\sim 46.6 \pm 10$ & No & Partial (50) & Beans (flour) & Wheat & $1 \mathrm{yr}$ \\
\hline Finley et al. ${ }^{25}(\mathrm{H})$ & $\begin{array}{c}40(20 \mathrm{M}, 20 \mathrm{~F}) \text { healthy } \\
\text { patients; US }\end{array}$ & $\sim 37.4 \pm 11$ & No & Partial (130) & Beans (whole) & Chicken soup & $12 \mathrm{wk}$ \\
\hline Finley et al. ${ }^{25}$ (pre-MS) & $\begin{array}{c}40(20 \mathrm{M}, 20 \mathrm{~F}) \text { with } \\
\text { pre-MS; US }\end{array}$ & $\sim 42.4 \pm 10$ & No & Partial (130) & Beans (whole) & Chicken soup & $12 \mathrm{wk}$ \\
\hline Gormley et al. ${ }^{37}$ & $\begin{array}{l}53 \text { healthy patients; } \\
\text { Ireland }\end{array}$ & Most 30-50 & NR & Partial ( 59) & Peas (whole) & Corn flakes & $6 w k$ \\
\hline Gravel et al. ${ }^{26}$ & $\begin{array}{l}114 \text { women with } \\
\text { pre-MS; Canada }\end{array}$ & $\sim 51.2 \pm 8.6$ & No & Partial ( 81) & Mixed (whole) & No pulses & 16 wk \\
\hline Hermsdorff et al. ${ }^{8}$ & $\begin{array}{c}30(17 \mathrm{M}, 13 \mathrm{~F}) \text { obese } \\
\text { patients; Spain }\end{array}$ & $36 \pm 8$ & No & None ( 198) & Mixed (whole) & No pulses & $8 w k$ \\
\hline Hodgson et al..$^{33}$ & $\begin{array}{l}74(26 \mathrm{M}, 48 \mathrm{~F}) \\
\text { overweight or obese } \\
\text { patients; Australia }\end{array}$ & $\sim 57.9 \pm 7.9$ & Yes & Partial ( 64) & Beans (flour) & White bread & $16 \mathrm{wk}$ \\
\hline Jenkins et al. ${ }^{35}$ & $\begin{array}{l}121(61 \mathrm{M}, 60 \mathrm{~F}) \text { with } \\
\text { type } 2 \text { diabetes; Canada }\end{array}$ & $\sim 59.5 \pm 12.8$ & Yes & None (196) & Mixed (whole) & $\begin{array}{l}\text { High-fibre } \\
\text { foods }\end{array}$ & $12 \mathrm{wk}$ \\
\hline \multicolumn{8}{|l|}{ Crossover } \\
\hline Abeysekara et al. ${ }^{36 * *}$ & $\begin{array}{c}87 \text { (30 M, } 57 \mathrm{~F}) \\
\text { Canada }\end{array}$ & $59.7 \pm 6.3$ & No & Partial (250) & Mixed (whole) & No pulses & $8 w k$ \\
\hline Cobiac et al..$^{24}$ & $\begin{array}{l}20 \text { men with } \mathrm{HC} ; \\
\text { Australia }\end{array}$ & $(29-65)$ & No & Partial ( 377) & Beans (whole) & Spaghetti & $4 \mathrm{wk}$ \\
\hline Duane et al. ${ }^{7}$ & 9 healthy men; US & $58(41-78)$ & NR & All $(\sim 251)$ & Mixed (NR) & No pulses & $6-7 \mathrm{wk}$ \\
\hline Jimenez-Cruz et al. ${ }^{34}$ & $\begin{array}{c}8 \text { (sex NR) with type } 2 \\
\text { diabetes; US }\end{array}$ & $51 \pm 3$ & No & None (NR) & Beans (whole) & $\begin{array}{l}\text { High-glycemic } \\
\text { foods }\end{array}$ & 3 wk \\
\hline Mackay et al. ${ }^{27}$ & $\begin{array}{l}39 \text { (22 M, 17 F) with } \\
\text { HC; New Zealand }\end{array}$ & $\sim 47(28-66)$ & NR & Partial (80) & $\begin{array}{c}\text { Beans } \\
\text { (whole/flour) }\end{array}$ & $\begin{array}{l}\text { Low-fibre } \\
\text { foods }\end{array}$ & $6 \mathrm{wk}$ \\
\hline Marinangeli et al. ${ }^{38}$ & $\begin{array}{l}23(7 \mathrm{M}, 16 \mathrm{~F}) \text { overweight } \\
\text { or obese patients } \\
\text { with HC; Canada }\end{array}$ & $\sim 52.0 \pm 10.6$ & No & All ( 138) & Peas (flour) & White flour & 4 wk \\
\hline Pittaway et al. ${ }^{28}$ & $\begin{array}{l}47(19 \mathrm{M}, 28 \mathrm{~F}) \\
\text { Australia }\end{array}$ & $53 \pm 9.8$ & No & Partial (140) & $\begin{array}{c}\text { Chickpeas } \\
\text { (whole/flour) }\end{array}$ & $\begin{array}{l}\text { Whole } \\
\text { wheat }\end{array}$ & $5-6$ wk \\
\hline Pittaway et al. ${ }^{29}$ & $\begin{array}{l}27 \text { (10 M, 17 F); } \\
\text { Australia }\end{array}$ & $50.6 \pm 10.5$ & No & Partial (140) & $\begin{array}{l}\text { Chickpeas } \\
\text { (whole/flour) }\end{array}$ & $\begin{array}{l}\text { Whole } \\
\text { wheat }\end{array}$ & $5 w k$ \\
\hline Shams et al..$^{30}$ & $\begin{array}{c}30 \text { patients with type } 2 \\
\text { diabetes; Iran }\end{array}$ & $50.2 \pm 3.8$ & No & Partial (50) & Lentils (whole) & No pulses & 6 wk \\
\hline Winham et al. ${ }^{31}$ & $\begin{array}{l}23(10 \mathrm{M}, 13 \mathrm{~F}) \\
\text { with HC; US }\end{array}$ & $45.9 \pm 10.6$ & No & Partial $(\sim 50)$ & Beans (whole) & Carrots & $8 w k$ \\
\hline Winham et al. ${ }^{20}(\mathrm{COM}) \dagger \dagger$ & $\begin{array}{l}16(7 \mathrm{M}, 9 \mathrm{~F}) \text { with } \\
\text { mild IR; US }\end{array}$ & $43 \pm 12$ & No & Partial $(\sim 50)$ & $\begin{array}{l}\text { Beans and } \\
\text { peas (whole) }\end{array}$ & Carrots & $8 w k$ \\
\hline Zhang et al. ${ }^{32}$ (IS) & 36 men with IS; US & $53.8 \pm 7.6$ & No & All (250) & Beans (whole) & Chicken & 4 wk \\
\hline Zhang et al. ${ }^{32}$ (IR) & 28 men with IR; US & $55.5 \pm 8$ & No & All (250) & Beans (whole) & Chicken & $4 \mathrm{wk}$ \\
\hline \multicolumn{8}{|c|}{ 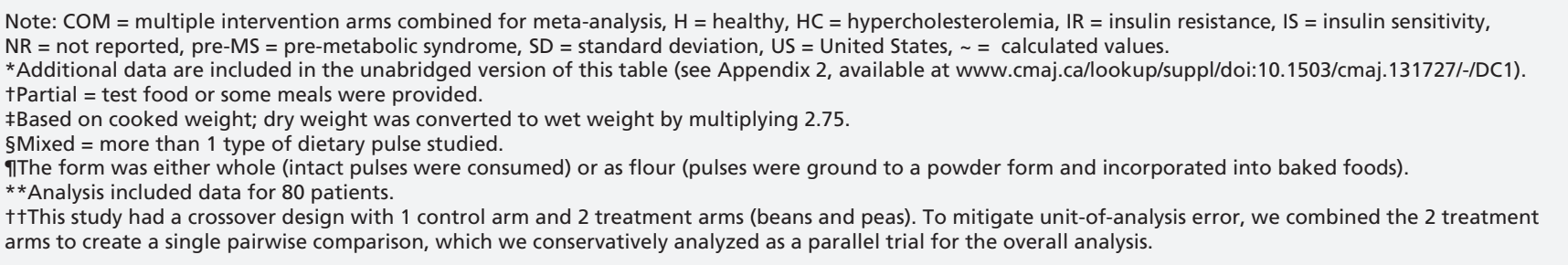 } \\
\hline
\end{tabular}


were provided) in 5 trials, partially controlled (only test foods were provided) in 17 trials and not metabolically controlled (dietary advice was offered) in 4 trials.

Thirteen of the trials had a crossover design. Twenty-two trials were conducted in an outpatient setting, 2 in an inpatient setting and 2 in a combination of settings. The median followup period was 6 (range 3-52) weeks. Funding of the trials was from publicly funded agencies alone (13 trials), a combination of agency and industry sources ( 7 trials), and industry alone (4 trials); the source of funding was not clearly stated in 2 trials.

According to the total methodologic quality scores, 7 of the 22 reports were of high quality (Appendix 3, available at www.cmaj.ca/lookup /suppl/doi:10.1503/cmaj.131727/-/DC1). The results of the risk-of-bias assessment are shown in
Table 2 and Appendix 4 (available at www.cmaj.ca /lookup/suppl/doi:10.1503/cmaj.131727/-/DC1).

\section{Gastrointestinal symptoms}

Eleven trials provided data on gastrointestinal symptoms reported by the participants. Upset stomach was reported in 4 of the 11 trials, flatulence in 7 , bloating in 6 , diarrhea and constipation in 1 trial each and increased stool frequency in 3 trials. Most of the studies reported that symptoms improved over the course of the dietary pulse intervention. Only 2 trials had one or two participants reporting gastrointestinal symptoms as a reason for withdrawal from the study. ${ }^{26,29}$

\section{Effect on lipid targets}

Twenty-one reports ( 25 trials) provided data on the effect of dietary pulse intake on LDL cholesterol (Figure 2). Intervention diets significantly reduced

Table 2: Results of assessment of the 22 reports for risk of bias*

\begin{tabular}{|c|c|c|c|c|c|}
\hline Study & $\begin{array}{c}\text { Sequence } \\
\text { generationt }\end{array}$ & $\begin{array}{c}\text { Allocation } \\
\text { concealment }\end{array}$ & Blinding§ & $\begin{array}{c}\text { Incomplete } \\
\text { outcome dataף }\end{array}$ & $\begin{array}{l}\text { Selective outcome } \\
\text { reporting** }\end{array}$ \\
\hline Abete et al. ${ }^{6}$ & Unclear & Unclear & Unclear & Low & Unclear \\
\hline Abeysekara et al. ${ }^{36}+\dagger$ & Low & Low & High & Low & Low \\
\hline Anderson et al. ${ }^{22}$ & Unclear & Unclear & Low & Low & Unclear \\
\hline Anderson et al. ${ }^{17}$ & Unclear & Unclear & Low & Low & Unclear \\
\hline Belski et al. ${ }^{23}$ & Low & Low & Low & Low & Low \\
\hline Cobiac et al. ${ }^{24}$ & Unclear & Unclear & Unclear & Low & Unclear \\
\hline Duane et al. ${ }^{7}$ & Unclear & Unclear & Low & Low & Unclear \\
\hline Finley et al. ${ }^{25}$ & Unclear & Unclear & Unclear & Low & Unclear \\
\hline Gormley et al. ${ }^{37}$ & Unclear & Unclear & Unclear & Low & Unclear \\
\hline Gravel et al. ${ }^{26}$ & Low & Low & Low & High & Low \\
\hline Hermsdorff et al. ${ }^{8}$ & Unclear & Unclear & Unclear & Low & Low \\
\hline Hodgson et al. ${ }^{33}$ & Low & Low & Low & Low & Low \\
\hline Jenkins et al. ${ }^{35}$ & Unclear & Low & Low & Low & Low \\
\hline Jimenez-Cruz et al. ${ }^{34}$ & Unclear & Unclear & Unclear & Low & Unclear \\
\hline Mackay et al. ${ }^{27}$ & Unclear & Unclear & Low & Low & Low \\
\hline Marinangeli et al. ${ }^{38}$ & Unclear & Unclear & Low & Low & Low \\
\hline Pittaway et al. ${ }^{28}$ & Unclear & Unclear & Low & Low & Unclear \\
\hline Pittaway et al. ${ }^{29}$ & Unclear & Unclear & Low & Low & Unclear \\
\hline Shams et al. ${ }^{30}$ & Unclear & Unclear & Unclear & Low & Unclear \\
\hline Winham et al. ${ }^{31}$ & Low & Low & Unclear & Low & Low \\
\hline Winham et al. ${ }^{20}$ & Unclear & Unclear & Unclear & Low & Low \\
\hline Zhang et al. ${ }^{32}$ & Unclear & Unclear & Low & Low & Unclear \\
\hline \multicolumn{6}{|c|}{$\begin{array}{l}\text { *The Cochrane risk-of-bias tool }{ }^{19} \text { was used to assess the risk of bias for each study. High risk }=\text { methodologic flaw in study design was likely to have affected the } \\
\text { true outcome, low risk = the effect of the study's methodologic flaw was deemed inconsequential to the true outcome, unclear risk = insufficient information was } \\
\text { given to assess risk. } \\
\text { †Assessed the randomization method and whether it would produce comparable groups. } \\
\text { ¥Assessed whether investigators could tell to which treatment participants were going to be randomly allocated. } \\
\S \text { Assessed whether investigators and/or participants were aware of group allocation. } \\
\text { १Assessed whether missing outcome data, including loss to follow-up and exclusion from analysis, may have affected the true outcome. } \\
\text { **Assessed whether investigators pre-registered the trial or specified primary and secondary outcomes, or both. } \\
\dagger+T h e \text { results of this trial may have been influenced by another potential source of bias: participants in the dietary pulse arm were given both food and dietary } \\
\text { advice throughout the study, whereas participants in the control arm were simply told to keep following their usual dietary habits. }\end{array}$} \\
\hline
\end{tabular}


LDL cholesterol compared with control diets (mean difference $-0.17 \mathrm{mmol} / \mathrm{L}, 95 \% \mathrm{CI}-0.25$ to $-0.09 \mathrm{mmol} / \mathrm{L}$ ); however, inter-study heterogeneity was high $\left(I^{2}=80 \%\right)$. The sensitivity analysis did not identify any of the studies as exerting undue influence on the overall results. None of the findings from the a priori subgroup analyses could explain the source of the inter-study heterogeneity. The post-hoc subgroup analysis by sex, however, showed that studies with more men tended to show a greater reduction in LDL cholesterol than those with more women, with a corresponding reduction in the $I$ value from $80 \%$ in our primary analysis to $53 \%$. The post-hoc subgroup analysis by baseline triglyceride levels did not show a significant effect. (The findings from the subgroup analyses are shown in Appendices 5, 6 and 7, available at www .cmaj.ca/lookup/suppl/doi:10.1503/cmaj.131727//DC1).

In the one trial that investigated the effect of dietary pulse intake on apolipoprotein $\mathrm{B},{ }^{26}$ there was no significant difference in effect between the intervention and control diets (mean difference $0.02 \mathrm{~g} / \mathrm{L}, 95 \% \mathrm{CI}-0.04$ to $0.08 \mathrm{~g} / \mathrm{L})$.

The effect of dietary pulse intake on nonHDL cholesterol was investigated in 20 reports (22 trials), and the results are shown in Figure 3. The effect between the intervention and the control diets did not differ significantly (mean difference $-0.09 \mathrm{mmol} / \mathrm{L}, 95 \% \mathrm{CI}-0.19$ to $0.00 \mathrm{mmol} / \mathrm{L}$ ); however, inter-study heterogeneity was very high $\left(I^{2}=98 \%\right)$. Sensitivity analy-

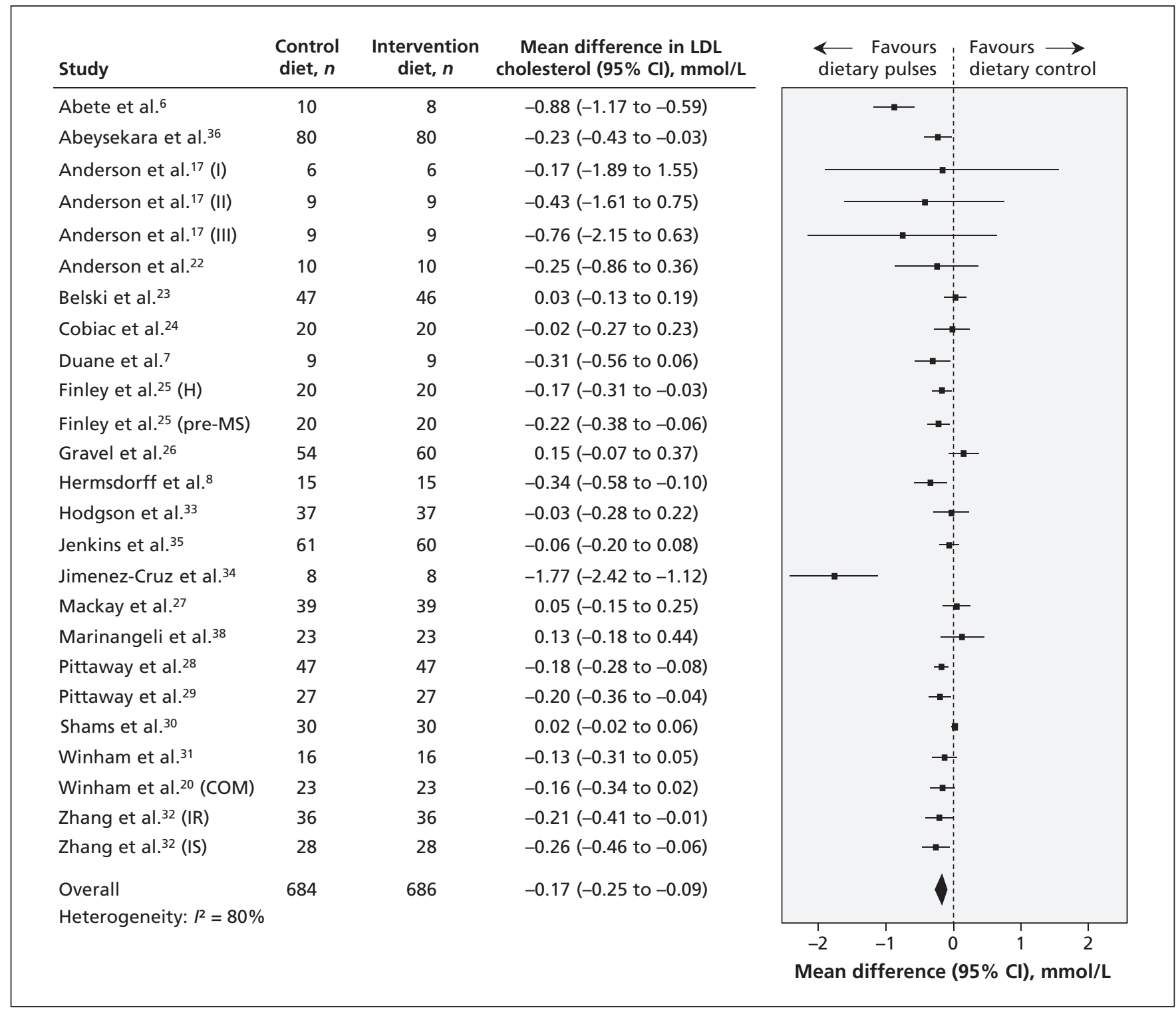

Figure 2: Effect of isocaloric exchange of intervention diets with dietary pulses for control diets without dietary pulses on low-density lipoprotein (LDL) cholesterol. Data are expressed as mean differences in LDL with $95 \%$ confidence intervals (Cls). Values less than zero favour intake of dietary pulses. COM = multiple intervention arms combined for meta-analysis, $\mathrm{H}=\mathrm{healthy}$, IR = insulin resistance, IS = insulin sensitivity, pre-MS = pre-metabolic syndrome. 
ses showed that the pooled effect size became significant when any of the 6 trials that favoured the effect of the control diet t $^{6,8,22,23,26,38}$ was removed. The use of a correlation coefficient of 0.25 did not alter conclusions, but a correlation coefficient of 0.75 resulted in a significant reduction in non-HDL cholesterol favouring the dietary pulse intervention.

In the a priori subgroup analyses, higher fibre intake in the intervention arm than in the control arm showed a significantly greater reduction in non-HDL cholesterol. The post-hoc subgroup analyses by sex and baseline triglyceride levels did not show significant effects. (Results of these subgroup analyses are shown in Appendices 7, 8 and 9, available at www.cmaj.ca/lookup/suppl /doi:10.1503/cmaj.131727/-/DC1).

\section{Publication bias}

Inspection of funnel plots for evidence of publi- cation bias and the Egger test result revealed asymmetry favouring small studies with LDL cholesterol-reducing effects (Appendix 10A, available at www.cmaj.ca/lookup/suppl/doi :10.1503/cmaj.131727/-/DC1). Both the Begg test and the trim-and-fill method, however, showed no significant evidence of undue small-study effects on the pooled LDL cholesterol estimate. None of the other outcomes showed significant evidence of publication bias (Appendix 10B).

\section{Interpretation}

Our meta-analysis included data from $26 \mathrm{RCTs}$ of the effect of dietary pulses (beans, chickpeas, lentils and peas) on established therapeutic lipid targets for cardiovascular risk reduction in 1037 predominantly middle-age, normolipidemic or hyperlipidemic adults at moderate risk of coronary artery disease. The pooled analyses sug-

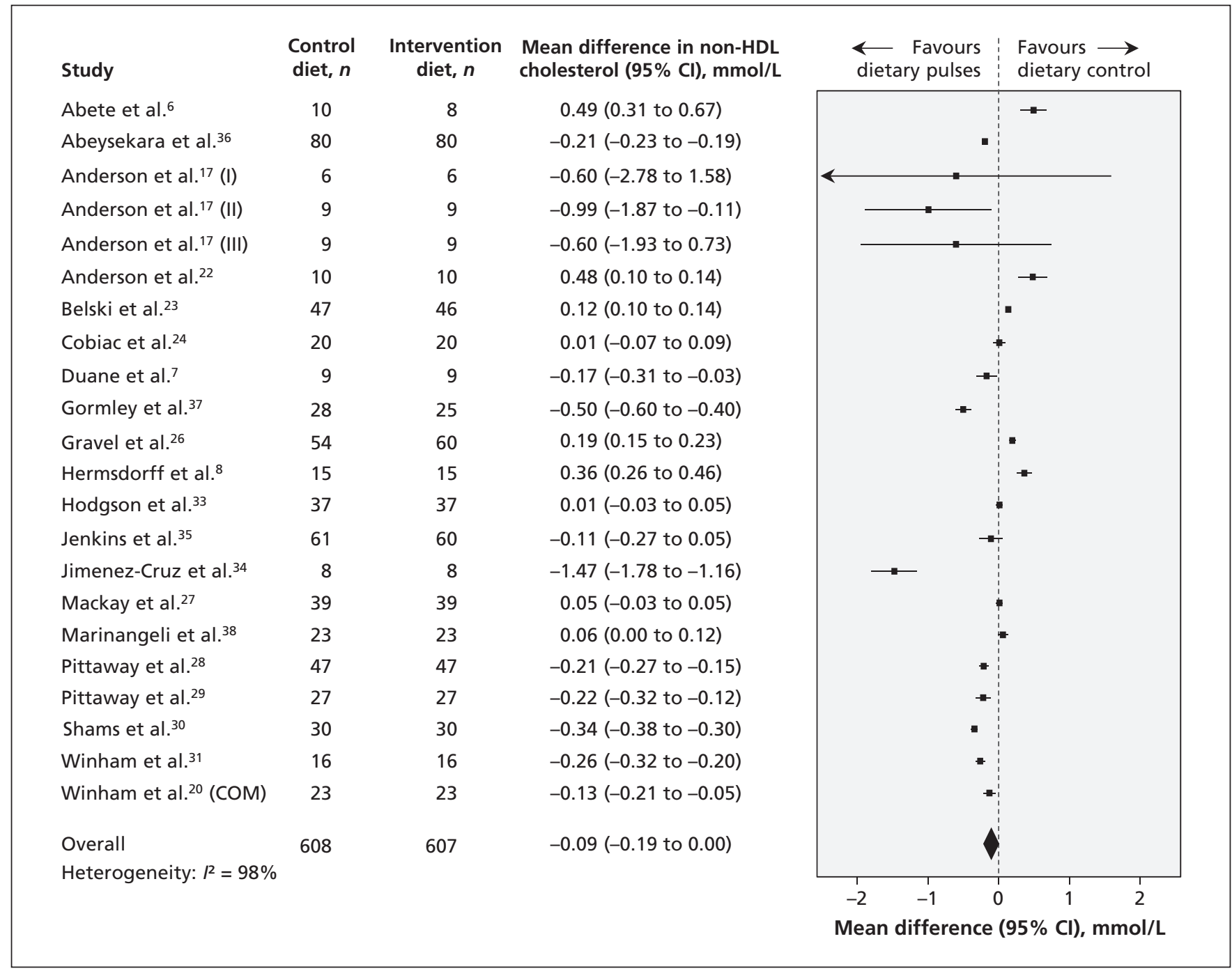

Figure 3: Effect of isocaloric exchange of intervention diets with dietary pulses for control diets without dietary pulses on non-highdensity lipoprotein (non-HDL) cholesterol. Data are expressed as mean differences in non-HDL with $95 \%$ confidence intervals (Cls). Values less than zero favour intake of dietary pulses. COM = multiple intervention arms combined for meta-analysis. 
gested a significant reduction in LDL cholesterol of $0.17 \mathrm{mmol} / \mathrm{L}$ at a median dose of $130 \mathrm{~g} / \mathrm{d}$ of pulses (about 1 serving daily) over a median follow-up of 6 weeks. We found no significant effect of dietary pulse intake on apolipoprotein B and non-HDL cholesterol. Most of the studies reported that gastrointestinal symptoms improved over the course of the dietary intervention.

We analyzed the effect of dietary pulse intake on all established lipid risk factors for coronary artery disease, including LDL cholesterol, apolipoprotein B and non-HDL cholesterol. The observed reduction in LDL cholesterol is consistent with that reported in 2 previous meta-analyses; ${ }^{39,40}$ however, we limited our analysis to RCTs with at least 3 weeks of follow-up, in conformity with US Food and Drug Administration guidelines. ${ }^{16}$

We found significant inter-study heterogeneity in our pooled analysis of the effect of dietary pulse intake on LDL cholesterol. Although none of our a priori subgroup analyses could explain the source of the heterogeneity, our post-hoc subgroup analysis by sex showed that there was a greater reduction in LDL cholesterol in studies with more men. Men may respond more favourably because they tend to have higher levels of LDL cholesterol than pre- and postmenopausal women of similar age taking hormone replacement therapy, and they tend to have poorer dietary habits and thus better responses to healthier diets. Although sex was found to have a significant modification of effect on LDL cholesterol, the level of inter-study heterogeneity was still substantial; future analyses are needed to explore other sources of heterogeneity.

Despite the high level of inter-study heterogeneity, the effect of dietary pulses on LDL cholesterol should not be underestimated. A previous meta-analysis of 19 trials involving more than 18000 participants showed that trials of statins and those of non-statins including dietary interventions had a similar 1-to-1 association between LDL cholesterol and cardiovascular mortality. ${ }^{41}$ That is, a $1 \%$ reduction in LDL cholesterol translated to a $1 \%$ reduction in cardiovascular mortality. Therefore, the reduction of $5 \%$ observed in our meta-analysis suggests a potential risk reduction of 5\%-6\% in major vascular events. ${ }^{42}$ This is important especially for patients with hypercholesterolemia who prefer dietary approaches to managing their cholesterol levels or for those who cannot tolerate statin therapies. Finally, the mean differences in LDL cholesterol between the intervention and control diets in most of the trials (23 of 25) fell within the $95 \% \mathrm{CI}$ of the pooled estimate, which suggests robustness in our data and increasing confidence in our conclusions.

Our findings regarding non-HDL cholesterol were complicated by a very high level of heterogeneity. The a priori subgroup analysis found a significant reduction in non-HDL cholesterol when the intervention arm had greater fibre intake than the control arm. Diets high in fibre have been shown to reduce non-HDL cholesterol $^{43}$ and have been inversely associated with cardiovascular disease risk. ${ }^{44}$ However, a substantial amount of heterogeneity remained unexplained. In the sensitivity analysis, recalculation of the effect size after the removal of any of the 6 trials that favoured the effect of the control diet showed a significant reduction in non-HDL cholesterol. However, there were no unique characteristics common among these trials that would lead us to believe that there was bias in these analyses.

\section{Limitations}

Our study has limitations. First, most of the trials were of low methodologic quality, were shorter than 3 months and did not report enough data to judge risk of bias. In addition, only one trial each reported apolipoprotein B and non-HDL cholesterol values for participants.

Second, publication bias was a possibility. Although we observed plot asymmetry and a significant Egger test result favouring smallstudy effects on LDL cholesterol, the Begg test did not show similar findings, and the trim-and-fill method did not show significant evidence of undue small-study effects on our estimate. Four RCTs involving a total of 307 participants at low and high risk of cardiovascular disease with a followup of 6-12 weeks are underway (ClinicalTrial.gov registration nos. NCT01562171, NCT01661543, NCT00800033 and NCT01114399). Their findings will contribute to the evidence on the effect of dietary pulse intake on lipid risk factors for cardiovascular disease. They may also address some of our concerns about publication bias.

\section{Conclusion}

Our findings have implications for cardiovascular health. Dietary pulse intake resulted in a modest reduction in LDL cholesterol of $0.17 \mathrm{mmol} / \mathrm{L}$ (equivalent to a reduction of about $5 \%$ from baseline). The median dietary pulse intake was $130 \mathrm{~g} / \mathrm{d}$ (about 1 serving daily), which may prove challenging in some Western countries given that the current median intake level in the United States is 0.2 servings daily, ${ }^{45}$ and in Canada only $13 \%$ consume dietary pulses on a given day, with a median intake of only about 0.5 servings daily among those who do consume them. ${ }^{46}$ However, this intake level is reasonable and is currently consumed by many cultures without reports of adverse effects that would limit consumption. 
Because most of the trials in our meta-analysis were conducted on a background of heart-healthy diets (e.g., more than $20-25 \mathrm{~g} / \mathrm{d}$ of fibre and less than $10 \%$ energy from saturated fat), the $5 \%$ reduction in LDL cholesterol observed with the dietary pulse diets can be considered in addition to the 5\%-10\% reduction in LDL cholesterol expected from the heart-healthy diets alone. ${ }^{47}$ However, because most of the trials were of low methodologic quality and short duration, and because our analyses of apolipoprotein $\mathrm{B}$ and non-HDL cholesterol were limited in the number of studies reporting these values, longer, betterdesigned trials are needed, particularly ones that will assess apolipoprotein B and non-HDL cholesterol. Because dietary pulse intake may have beneficial effects on other cardiometabolic risk factors, including body weight, blood pressure and glucose control, ${ }^{48}$ future systematic reviews and meta-analyses should evaluate the effects of such dietary interventions on these outcomes and others, to address factors that contribute to residual cardiovascular disease risk.

\section{References}

1. National Cholesterol Education Program Expert Panel on Detection E. Third report of the National Cholesterol Education Program (NCEP) Expert Panel on Detection, Evaluation, and Treatment of High Blood Cholesterol in Adults (Adult Treatment Panel III) final report. Circulation 2002;106:3143-421.

2. Canadian Diabetes Association Clinical Practice Guidelines Expert Committee. Canadian Diabetes Association 2013 clinical practice guidelines for the prevention and management of diabetes in Canada. Can J Diabetes 2013;37(Suppl 1):S1-212.

3. American Diabetes Association. 2013 Clinical practice guidelines. Diabetes Care 2013;36(Suppl 1):S1-110.

4. Anderson TJ, Gregoire J, Hegele RA, et al. 2012 update of the Canadian Cardiovascular Society guidelines for the diagnosis and treatment of dyslipidemia for the prevention of cardiovascular disease in the adult. Can J Cardiol 2013;29:151-67.

5. Bazzano LA, He J, Ogden LG, et al. Legume consumption and risk of coronary heart disease in US men and women: NHANES epidemiologic follow-up study. Arch Intern Med 2001;161:2573-8.

6. Abete I, Parra D, Martinez JA. Legume-, fish-, or high-proteinbased hypocaloric diets: effects on weight loss and mitochondrial oxidation in obese men. J Med Food 2009;12:100-8

7. Duane WC. Effects of legume consumption on serum cholesterol, biliary lipids, and sterol metabolism in humans. J Lipid Res 1997; 38:1120-8.

8. Hermsdorff $\mathrm{HH}$, Zulet MA, Abete I, et al. A legume-based hypocaloric diet reduces proinflammatory status and improves metabolic features in overweight/obese subjects. Eur J Nutr 2011; 50:61-9.

9. How do I follow a healthy diet? Dallas (TX): American Health Association; 2012.

10. Dietary guidelines for Americans, 2010. Washinton (DC): US Department of Agriculture: Center for Nutrition Policy and Promotion; 2011.

11. Diet, nutrition and the prevention of chronic diseases. Geneva (Switzerland): World Health Organization; 2003.

12. Lichtenstein AH, Appel LJ, Brands M, et al. Diet and lifestyle recommendations revision 2006: a scientific statement from the American Heart Association Nutrition Committee. Circulation 2006;114:82-96.

13. Mann JI, De Leeuw I, Hermansen K, et al.; Diabetes and Nutrition Study Group (DNSG) of the European Association. Evidencebased nutritional approaches to the treatment and prevention of diabetes mellitus. Nutr Metab Cardiovasc Dis 2004;14:373-94.

14. Higgins JPT, Green S, editors. Cochrane handbook for systematic reviews of interventions. Version 5.1.0. London (UK): Cochrane Collaboration; 2011. Available: www.cochrane-handbook.org (accessed 2014 Mar. 20).

15. Moher D, Liberati A, Tetzlaff J, et al. Preferred reporting items for systematic reviews and meta-analyses: the PRISMA statement. BMJ 2009;339:b2535.

16. Guidance for industry: evidence-based review system for the scientific evaluation of health claims. Silver Spring (MD): US Food and Drug Administration; 2009. Available: www.fda.gov /OHRMS/DOCKETS/98fr/FDA-2007-D-0371-gdl.pdf (accessed 2014 Mar. 20).

17. Anderson JW, Gustafson NJ, Spencer DB, et al. Serum lipid response of hypercholesterolemic men to single and divided doses of canned beans. Am J Clin Nutr 1990;51:1013-9.

18. Heyland DK, Novak F, Drover JW, et al. Should immunonutrition become routine in critically ill patients? A systematic review of the evidence. JAMA 2001;286:944-53.

19. Higgins JP, Altman DG, Gøtzsche PC, et al. The Cochrane Collaboration's tool for assessing risk of bias in randomised trials. BMJ 2011;343:d5928.

20. Winham DM, Hutchins AM, Johnston CS. Pinto bean consumption reduces biomarkers for heart disease risk. J Am Coll Nutr 2007;26:243-9.

21. Elbourne DR, Altman DG, Higgins JP, et al. Meta-analyses involving cross-over trials: methodological issues. Int J Epidemiol 2002;31:140-9.

22. Anderson JW, Story L, Sieling B, et al. Hypocholesterolemic effects of oat-bran or bean intake for hypercholesterolemic men. Am J Clin Nutr 1984;40:1146-55.

23. Belski R, Mori TA, Puddey IB, et al. Effects of lupin-enriched foods on body composition and cardiovascular disease risk factors: a 12-month randomized controlled weight loss trial. Int J Obes (Lond) 2011;35:810-9.

24. Cobiac L, McArthur R, Nestel PJ. Can eating baked beans lower plasma cholesterol? Eur J Clin Nutr 1990;44:819-22.

25. Finley JW, Burrell JB, Reeves PG. Pinto bean consumption changes SCFA profiles in fecal fermentations, bacterial populations of the lower bowel, and lipid profiles in blood of humans. J Nutr 2007;137:2391-8.

26. Gravel K, Lemieux S, Asselin G, et al. Effects of pulse consumption in women presenting components of the metabolic syndrome: a randomized controlled trial. Mediterr J Nutr Metab 2010;3:143-51.

27. Mackay S, Ball MJ. Do beans and oat bran add to the effectiveness of a low-fat diet? Eur J Clin Nutr 1992;46:641-8.

28. Pittaway JK, Ahuja KD, Cehun M, et al. Dietary supplementation with chickpeas for at least 5 weeks results in small but significant reductions in serum total and low-density lipoprotein cholesterols in adult women and men. Ann Nutr Metab 2006;50: 512-8.

29. Pittaway JK, Ahuja KD, Robertson IK, et al. Effects of a controlled diet supplemented with chickpeas on serum lipids, glucose tolerance, satiety and bowel function. J Am Coll Nutr 2007; 26:334-40.

30. Shams H, Tahbaz F, Entezari MH, et al. Effects of cooked lentils on glycemic control and blood lipids of patients with type 2 diabetes. ARYA Atheroscler 2008;4:1-5.

31. Winham DM, Hutchins AM. Baked bean consumption reduces serum cholesterol in hypercholesterolemic adults nutrition research. Nutr Res 2007;27:380-6.

32. Zhang Z, Lanza E, Kris-Etherton PM, et al. A high legume low glycemic index diet improves serum lipid profiles in men. Lipids 2010;45:765-75

33. Hodgson JM, Lee YP, Puddey IB, et al. Effects of increasing dietary protein and fibre intake with lupin on body weight and composition and blood lipids in overweight men and women. Int J Obes (Lond) 2010;34:1086-94.

34. Jimenez-Cruz A. Turnbull WH, Bacardi-Gascón M. A high-fiber moderate-glycemic-index, Mexican style diet improves dyslipidemia in individuals with type 2 diabetes. Nutr Res 2004;24:19-27.

35. Jenkins DJ, Kendall CW, Augustin LS, et al. Effect of legumes as part of a low glycemic index diet on glycemic control and cardiovascular risk factors in type 2 diabetes mellitus: a randomized controlled trial. Arch Intern Med 2012;172:1653-60.

36. Abeysekara S, Chilibeck PD, Vatanparast H, et al. A pulse-based diet is effective for reducing total and LDL-cholesterol in older adults. Br J Nutr 2012;108(Suppl 1):S103-10.

37. Gormley TR, Kevany J, O'Donnell B, et al. Effect of peas on serum cholesterol levels in humans. Int J Food Sci Technol 1979;3:101-9.

38. Marinangeli CP, Jones PJ. Whole and fractionated yellow pea flours reduce fasting insulin and insulin resistance in hypercholesterolaemic and overweight human subjects. Br J Nutr 2011; 105:110-7.

39. Anderson JW, Major AW. Pulses and lipaemia, short- and longterm effect: potential in the prevention of cardiovascular disease. Br J Nutr 2002;88(Suppl 3):S263-71.

40. Bazzano LA, Thompson AM, Tees MT, et al. Non-soy legume consumption lowers cholesterol levels: a meta-analysis of randomized controlled trials. Nutrition, metabolism, and cardiovas- 
cular diseases. Nutr Metab Cardiovasc Dis 2011;21:94-103.

41. Robinson JG, Smith B, Maheshwari N, et al. Pleiotropic effects of statins: Benefit beyond cholesterol reduction? A metaregression analysis. J Am Coll Cardiol 2005;46:1855-62.

42. Mihaylova B, Emberson J, Blackwell L, et al.; Cholesterol Treatment Trialists' (CTT) Collaborators. The effects of lowering LDL cholesterol with statin therapy in people at low risk of vascular disease: meta-analysis of individual data from 27 randomised trials. Lancet 2012;380:581-90.

43. Reyna-Villasmil N, Bermudez-Pirela V, Mengual-Moreno E, et al Oat-derived beta-glucan significantly improves HDLC and diminishes LDLC and non-HDL cholesterol in overweight individuals with mild hypercholesterolemia. Am J Ther 2007;14:203-12.

44. Pereira MA, O'Reilly E, Augustsson K, et al. Dietary fiber and risk of coronary heart disease: a pooled analysis of cohort studies. Arch Intern Med 2004;164:370-6.

45. Guenther PM, Dodd KW, Reedy J, et al. Most Americans eat much less than recommended amounts of fruits and vegetables. J Am Diet Assoc 2006;106:1371-9.

46. Mudryj AN, Yu N, Hartman TJ, et al. Pulse consumption in Canadian adults influences nutrient intakes. Br J Nutr 2012;108 (Suppl 1):S27-36.

47. Jenkins DJ, Jones PJ, Lamarche B, et al. Effect of a dietary portfolio of cholesterol-lowering foods given at 2 levels of intensity of dietary advice on serum lipids in hyperlipidemia: a randomized controlled trial. JAMA 2011;306:831-9.

48. Sievenpiper JL, Kendall CW, Esfahani A, et al. Effect of non-oilseed pulses on glycaemic control: a systematic review and metaanalysis of randomised controlled experimental trials in people with and without diabetes. Diabetologia 2009;52:1479-95.

Competing interests: Vanessa Ha has received research support from the Canadian Institutes of Health Research (CIHR) and the World Health Organization (WHO) for work on a systematic review and meta-analysis commissioned by WHO of the relation of saturated fatty acids with health outcomes. She received a travel award to attend a science day hosted by PepsiCo Inc. and the New York Academy of Sciences. John Sievenpiper has received research support from the Calorie Control Council, the Coca-Cola Company (investigator initiated, unrestricted grant), Pulse Canada, and the International Tree Nut Council Nutrition Research and Education Foundation. He has received travel funding, speaker fees or honoraria from the American Heart Association, the American Society for Nutrition, the National Institute of Diabetes and Digestive and Kidney Diseases, the Canadian Diabetes Association, the Canadian Nutrition Society, the Calorie Control Council, the Diabetes and Nutrition Study Group of the European Association for the Study of Diabetes, the International Life Sciences Institute North America, the International Life Sciences Institute Brazil, the University of South Carolina, the University of Alabama at Birmingham, the Canadian Sugar Institute, Oldways Preservation Trust, the Nutrition Foundation of Italy, Abbott Laboratories, Pulse Canada, Dr. Pepper Snapple Group and the Coca-Cola Company. He is on the Clinical Practice Guidelines Expert Committee for Nutrition Therapy of both the Canadian Diabetes Association and the European Association for the Study of Diabetes, and he is on the American Society for Nutrition writing panel for a scientific statement on the metabolic and nutritional effects of fructose, sucrose and high-fructose corn syrup. He is a member of the Carbohydrate Quality Consortium and an unpaid scientific advisor for the Food, Nutrition and Safety Program of the International Life Science Institute North America. His wife is an employee of Unilever Canada. Russell de Souza is funded by a CIHR Postdoctoral Fellowship Award and has received research support from the CIHR, the Calorie Control Council, the Canadian Foundation for Dietetic Research and the Coca-Cola Company (investigator initiated, unrestricted grant). He has served as an external resource person to WHO's Nutrition Guidelines Advisory Group and received travel support from WHO to attend group meetings. He is the lead author of 2 systematic reviews and meta-analyses commissioned by WHO of the relation of saturated fatty acids and trans fatty acids with health outcomes. Laura Chiavaroli has received research support from the CIHR and the Agricultural Bioproducts Innovation Program through the Pulse Research Network (PURENet), and
Saskatchewan Pulse Growers. She is also a casual clinical research coordinator at Glycemic Index Laboratories. Vladimir Vuksan holds American (no. 7,326,404 B2) and Canadian (no. 2,410,556) patents for the use of viscous fibre blend in diabetes, metabolic syndrome and cholesterol lowering. He has received grant support from the Canadian Foundation for Innovation, the Korean National Institute of Horticultural and Herbal Science, CIHR, the Alternative Diabetes Research and Healthcare Foundation, the Ontario Ministry of Agriculture and Food, and the Canadian Diabetes Association. He is a vice-president and part owner of Glycemic Index Laboratories. Richard Bazinet has received research funding from Bunge Ltd., travel support from Unilever and consultant fees from Kraft Foods and Mead Johnson. Joseph Beyene has received research support from CIHR, the Calorie Control Council and the Coca-Cola Company (investigator initiated, unrestricted grant). Cyril Kendall has received research support from the Advanced Foods and Material Network, Agrifoods and Agriculture Canada, the Almond Board of California, the American Pistachio Growers, Barilla, the California Strawberry Commission, the Calorie Control Council, CIHR, the Canola Council of Canada, the CocaCola Company (investigator initiated, unrestricted grant), Hain Celestial, the International Tree Nut Council Nutrition Research and Education Foundation, Kellogg, Kraft, Loblaw Companies Ltd., Orafti, Pulse Canada, Saskatchewan Pulse Growers, Solae and Unilever. He has received travel funding, consultant fees or honoraria from Abbott Laboratories, the Almond Board of California, the American Peanut Council, the American Pistachio Growers, Barilla, Bayer, the Canola Council of Canada, the Coca-Cola Company, Danone, General Mills, the International Tree Nut Council Nutrition Research and Education Foundation, Kellogg, Loblaw Companies Ltd., the Nutrition Foundation of Italy, Oldways Preservation Trust, Orafti, Paramount Farms, the Peanut Institute, PepsiCo, Pulse Canada, Sabra Dipping Co., Saskatchewan Pulse Growers, Solae, Sun-Maid, Tate and Lyle, and Unilever. He is on the Dietary Guidelines Committee for the Diabetes Nutrition Study Group of the European Association for the Study of Diabetes and has served on the scientific advisory board for the Almond Board of California, the International Tree Nut Council, Oldways Preservation Trust, Paramount Farms and Pulse Canada. David Jenkins has served on the scientific advisory board of the Sanitarium Company, Agri-Culture and Agri-Food Canada, the Canadian Agriculture Policy Institute, the California Strawberry Commission, Loblaw Companies Ltd., Herbalife International, Nutritional Fundamentals for Health, Pacific Health Laboratories, Metagenics, Bayer Consumer Care, Orafti, Dean Foods, Kellogg's, Quaker Oats, Procter \& Gamble, the CocaCola Company, the Griffin Hospital (for the development of the NuVal scoring system), Abbott Laboratories, Pulse Canada, Saskatchewan Pulse Growers and the Canola Council of Canada. He received an honorarium from the US Department of Agriculture to present the 2013 W.O. Atwater Memorial Lecture. He has received honoraria for scientific advice from the Sanitarium Company, Orafti, the Almond Board of California, the American Peanut Council, the International Tree Nut Council Nutrition Research and Education Foundation, the Peanut Institute, Herbalife International, Pacific Health Laboratories, Nutritional Fundamental for Health, Barilla, Metagenics, Bayer Consumer Care, Unilever Canada and Netherlands, Solae, Oldways, Kellogg's, Quaker Oats, Procter \& Gamble, the Coca-Cola Company, the Griffin Hospital, Abbott Laboratories, the Canola Council of Canada, Dean Foods, the California Strawberry Commission, Haine Celestial, Pepsi, the Alpro Foundation, Pioneer HiBred International, DuPont Nutrition and Health, Spherix Consulting and WhiteWave Foods. He has been on the speakers panel for the Almond Board of California and has received research grants from Saskatchewan Pulse Growers, the Agricultural Bioproducts Innovation Program through the Pulse Research Network, the Advanced Foods and Material Network, Loblaw Companies Ltd., Unilever, Barilla, the Almond Board of California, the Coca-Cola Company, 
Solae, Haine Celestial, the Sanitarium Company, Orafti, the International Tree Nut Council Nutrition Research and Education Foundation, the Peanut Institute, the Canola and Flax Councils of Canada, the Calorie Control Council, the Canadian Institutes of Health Research, the Canada Foundation for Innovation and the Ontario Research Fund. He received the 2013 Award for Excellence in Research from the International Nut and Dried Fruit Council. He received funding and travel support from the Canadian Society of Endocrinology and Metabolism to produce mini cases for the Canadian Diabetes Association. He received travel support to attend meetings from Solae, the Sanitarium Company, Orafti, the Advanced Foods and Material Network, the Coca-Cola Company, the Canola and Flax Councils of Canada, Oldways Preservation Trust, Kellogg's, Quaker Oats, the Griffin Hospital, Abbott Laboratories, Dean Foods, the California Strawberry Commission, the American Peanut Council, Herbalife International, the Nutritional Fundamentals for Health, Metagenics, Bayer Consumer Care, Agri-Culture and Agri-Food Canada, the Canadian Agri-Food Policy Institute, Pepsi, the Almond Board of California, Unilever, the Alpro Foundation, the International Tree Nut Council, Barilla, Pulse Canada, the Saskatchewan Pulse Growers, the Soy Foods Association of North America, the Nutrition Foundation of Italy, NutraSource Diagnostics, the McDougall Program, the Toronto Knowledge Translation Group (St. Michael's Hospital), the Canadian College of Naturopathic Medicine, The Hospital for Sick Children, the Canadian Nutrition Society, the American Society of Nutrition, Arizona State University, Paolo Sorbini Foundation and the Institute of Nutrition, Metabolism and Diabetes. David Jenkins' wife is a director and partner of Glycemic Index Laboratories, and his sister received funding through a grant from the St. Michael's Hospital Foundation to develop a cookbook for the study reported in reference 47 . No competing interests were declared by Viranda Jayalath, Arnav Agarwal, Sonia Blanco Mejia, Marco Di Buono, Frank Sacks, Adam Bernstein, Penny KrisEtherton, Robert Josse and Lawrence Leiter.

Affiliations: Departments of Nutritional Sciences (Ha, de Souza, Chiavaroli, Blanco Mejia, Di Buono, Leiter, Vuksan, Bazinet, Josse, Kendall, Jenkins) and Medicine (Leiter, Josse, Jenkins), Faculty of Medicine, University of Toronto, Toronto, Ont.; the Toronto 3D Knowledge Synthesis and Clinical Trials Unit, Clinical Nutrition and Risk Factor Modification Centre (Ha, Sievenpiper, de Souza, Jayalath, Mirrahimi, Chiavaroli, Blanco Mejia, Leiter, Vuksan, Kendall), Li Ka Shing Knowledge Institute (Sievenpiper, Vuksan, Jenkins) and Division of Endocrinology (Josse), St. Michael's Hospital, Toronto, Ont.; Dalla Lana School of Public Health (Beyene), University of Toronto, Toronto, Ont.; Departments of Pathology and Molecular Medicine (Sievenpiper) and of Clinical Epidemiology and Biostatistics (de Souza, Beyene), Faculty of Health Sciences (Agarwal), McMaster University, Hamilton, Ont.;
American Heart Association (Di Buono), Houston, Tex.; Hospital for Sick Children Research Institute (Beyene), Toronto, Ont.; College of Pharmacy and Nutrition (Kendall), University of Saskatchewan, Saskatoon, Sask.; Department of Nutrition (Sacks, Bernstein), Harvard School of Public Health, Cambridge, Mass.; Channing Laboratory, Department of Medicine (Sacks), Brigham and Women's Hospital and Harvard Medical School (Sacks), Cambridge, Mass.; Wellness Institute of the Cleveland Clinic (Bernstein), Lyndhurst, Ohio; Department of Nutritional Sciences (Kris-Etherton), Pennsylvania State University, University Park, Pa.; Department of Human Health and Nutritional Sciences (Jayalath), College of Biological Sciences, University of Guelph, Guelph, Ont.; and School of Medicine, Faculty of Health Sciences (Mirrahimi), Queen's University, Kingston, Ont.

Contributors: Vanessa Ha, John Sievenpiper, Russell de Souza, Arash Mirrahimi, Laura Chiavaroli, Frank Sacks, Marco Di Buono, Adam Bernstein, Lawrence Leiter, Penny Kris-Etherton, Vladimir Vuksan, Joseph Beyene, Cyril Kendall and David Jenkins contributed to the conception and design of the study. Vanessa Ha, Russell de Souza, Viranda Jayalath and Arnav Agarwal acquired the data. Vanessa Ha, John Sievenpiper, Russell de Souza, Viranda Jayalath, Arash Mirrahimi, Arnav Agarwal, Joseph Beyene, Richard Bazinet, Robert Josse, Cyril Kendall and David Jenkins contributed to the analysis and interpretation of the data. Vanessa Ha and John Sievenpiper drafted the manuscript. All of the authors critically revised the manuscript for important intellectual content and approved the final version submitted for publication. All of the authors agreed to act as guarantors of the work.

Funding: This work was funded by a CIHR Knowledge Synthesis Grant (no. 119797) and by Loblaw Companies Limited. Vanessa Ha was supported by an Ontario Graduate Scholarship Award. Russell de Souza was funded by a CIHR Postdoctoral Fellowship Award. Richard Bazinet and David Jenkins were funded by the Government of Canada through the Canada Research Chair Endowment. None of the sponsors had a role in any aspect of the present study, including the design and conduct of the study; the collection, management, analysis and interpretation of the data; and the preparation, review and approval of the manuscript.

Acknowledgements: Aspects of this work were presented at Experimental Biology 2012 (San Diego, Calif., Apr. 21-25, 2012), the 15th annual Canadian Society for Endocrinology and Metabolism/Canadian Diabetes Association Professional Conference and Annual Meetings (Toronto, Ont., Oct. 10-13, 2012), the 53rd annual conference of the American College of Nutrition (Morristown, NJ, Nov. 14-17, 2012) and the 2014 Canadian Nutrition Society Conference on Advances in Dietary Carbohydrates and Fibre in Nutrition (Toronto, Ont., Jan. 14, 2014). 